\title{
Role of the Legionella pneumophila rtxA gene in amoebae
}

Department of Veterinary and Biomedical Sciences, University of Nebraska, Lincoln, 203 VBS, Fair and East Campus Loop, Lincoln, NE 68583, USA

\author{
Suat L. G. Cirillo, Ling Yan, Michael Littman, Mustapha M. Samrakandi \\ and Jeffrey D. Cirillo
}

\author{
Author for correspondence: Jeffrey D. Cirillo. Tel: +1 402472 8587. Fax: +1 4024729690 . \\ e-mail: jcirillo1@unl.edu
}

\begin{abstract}
Legionella pneumophila infects humans, causing Legionnaires' disease, from aerosols generated by domestic and environmental water sources. In aquatic environments $L$. pneumophila is thought to replicate primarily in protozoa. A 'repeats in structural toxin' (RTX) gene, rtxA, from L. pneumophila was identified recently that plays a role in entry and replication in human macrophages and also has the ability to infect mice. However, the role of this gene in the interaction of $L$. pneumophila with environmental protozoa and its distribution in different Legionella species has not been examined. Southern analyses demonstrated that $r t x A$ is present in all $L$. pneumophila isolates tested and correlates with species that have been shown to cause disease in humans. To evaluate the importance of $r t x A$ in the interaction with protozoa a series of studies was carried out in an environmental host for $L$. pneumophila, Acanthamoeba castellanii. The $L$. pneumophila rtxA gene plays a role in both adherence and entry into $A$. castellanii similar to that observed in human monocytic cells. Furthermore, it was found that $r$ txA is involved in intracellular survival and trafficking. In addition to demonstrating involvement of $r$ txA in the interaction of $L$. pneumophila with host cells, these data support a role for this gene both during disease in humans and in environmental reservoirs.
\end{abstract}

Keywords: phagocytosis, lysosomes, amoeba, pathogenesis, pneumonia

\section{INTRODUCTION}

Legionnaires' disease, a potentially lethal pneumonia, is the result of the ability of Legionella to enter, survive and replicate in macrophages (Davis et al., 1983; Nash et al., 1984; Winn \& Myerowitz, 1981). There are not any known animal reservoirs for L. pneumophila; however, protozoa in the environment provide an important environmental source of the bacteria that infect humans (Anand et al., 1983; Henke \& Seidel, 1986; Rowbotham, 1980, 1986). Since person to person transmission is not thought to occur (Yu et al., 1983), it appears that the natural hosts for L. pneumophila are these aquatic protozoa. In addition, the interaction of $L$. pneumophila with protozoa in the environment appears to enhance the ability to infect mammalian cells (Cirillo et al., 1994) and cause disease in animals (Brieland et al., 1996, 1997a, b; Cirillo et al., 1999). Thus, it is likely that the virulence mechanisms used by L. pneumophila to

Abbreviations: LY, lucifer yellow; RhR, rhodamine red; RTX, repeats in structural toxin. cause disease in humans evolved for optimal parasitism of protozoa.

Acanthamoeba castellanii, one potential environmental host for L. pneumophila (Rowbotham, 1980), undergoes a respiratory burst (Davies et al., 1991), produces oxygen radicals (Davies \& Edwards, 1991), expresses cell surface receptors (Allen \& Dawidowicz, 1990a) and has phagocytic mechanisms (Allen \& Dawidowicz, 1990b; Brown et al., 1975; Lock et al., 1987) similar to human macrophages. Furthermore, the mechanisms that provide a selective advantage in amoebae and macrophages are likely to be similar, since they enter by coiling phagocytosis (Bozue \& Johnson, 1996; Horwitz, 1984), inhibit lysosomal fusion (Bozue \& Johnson, 1996; Horwitz \& Maxfield, 1984) and localize to a rough endoplasmic reticulum-lined compartment $(\mathrm{Abu}$ Kwaik, 1996; B. S. Fields et al., 1986; Horwitz, 1983; Newsome et al., 1985; Swanson \& Isberg, 1995) in both cells. Certainly, a large number of potential virulence factors have been identified that affect the ability of $L$. pneumophila to survive in macrophages and amoebae (Cianciotto \& Fields, 1992; Gao et al., 1997; Pruckler et 
al., 1995; Segal \& Shuman, 1999). Although there are at least 42 Legionella species, approximately $90 \%$ of Legionnaires' disease cases in humans is caused by Legionella pneumophila (Marston et al., 1994, 1993; Reingold et al., 1984). Only 18 of the remaining species are infrequently associated with disease and the rest are primarily found in aquatic environments (Morris et al., 1979; Rowbotham, 1993). Even in these aquatic environments, L. pneumophila is the predominant species isolated (Fliermans et al., 1981).

These data suggest that L. pneumophila differs from other Legionella species in a manner that provides a selective advantage in both humans and the environment. Recently, our laboratory has identified three $L$. pneumophila loci that are involved in entry into human epithelial cells and macrophages (Cirillo et al., 2000). A gene present in one of these loci, $r t x A$, encodes a 'repeats in structural toxin' (RTX). RTX proteins are a large family of pore-forming cytolysins present in a number of different bacterial pathogens (Welch, 1991). The L. pneumophila $r t x A$ gene has previously been shown to play a role in entry and replication in macrophages and virulence in mice (Cirillo et al., 2001). In the current study, we examined the distribution of the $r t x A$ gene in different isolates of Legionella, including both environmental and clinical samples. Although the presence of $r t x A$ correlates with the ability to cause disease in humans we found that it also affects the ability of L. pneumophila to infect, traffic and survive in amoebae. These data indicate that $r t x A$ may affect both the severity of disease in humans and the ability of $L$. pneumophila to persist in environmental reservoirs.

\section{METHODS}

Bacterial strains and growth conditions. The L. pneumophila strains used for these studies were a streptomycin-resistant variant of AA100 transformed with the kanamycin-resistant vector pYUB289 (Cirillo et al., 2000) to control for effects of antibiotic resistance, the same strain containing an in-frame deletion of $r t x A$ and transformed with pJDC35 $(\Delta r t x A:: p J D C 35)$ for complementation or pJDC40 $(\Delta r t x A::$ pJDC40) as a vector control, as well as environmental and clinical isolates as listed in Table 1 . The $r t x A$ mutant is an in-frame deletion that includes only the amino-terminal 6 aa and carboxy-terminal 124 aa of RtxA (Cirillo et al., 2001). This mutation can be complemented by transformation of the mutant with the wild-type $r t x A$ gene (Cirillo et al., 2001). As described previously (Cirillo et al., 2001), pJDC35 is an integrating vector containing the complete $r t x A$ gene and pJDC40 is the same vector with $r t x A$ deleted. Strain $\psi \mathrm{lp} 55$ is an AA100 clone that has been passed 14 times in the laboratory until it is sodium-resistant and unable to replicate in monocytic cells (data not shown). All L. pneumophila strains other than $\psi \mathrm{lp} 55$, including the environmental and clinical isolates, were passaged no more than twice in our laboratory before use in these studies to prevent loss of virulence. L. pneumophila was grown on BCYE agar (Edelstein, 1981) for 3 days at $37^{\circ} \mathrm{C}$ in $5 \% \mathrm{CO}_{2}$. When necessary, kanamycin (Sigma) was added at a concentration of $25 \mu \mathrm{g} \mathrm{ml}^{-1}$ to bacterial growth medium.

Amoeba. The amoeba A. castellanii ATCC 30234 was grown in PYG broth in $75 \mathrm{~cm}^{2}$ tissue culture flasks in the dark at $23{ }^{\circ} \mathrm{C}$ (Cirillo et al., 1994; Moffat \& Tompkins, 1992).
Amoeba cells were brought into suspension by rapping the flask sharply and the number of viable cells was determined as described by Moffat \& Tompkins (1992).

Entry and adherence assays. Entry assays were carried out as described previously (Cirillo et al., 1994). Amoebae were seeded in 24-well tissue culture dishes (Falcon) at a concentration of $1.5 \times 10^{5}$ cells per well and allowed to adhere overnight at $23{ }^{\circ} \mathrm{C}$ in the dark. The cells were then washed with Ac buffer (HS) (Moffat \& Tompkins, 1992), $1 \mathrm{ml} \mathrm{HS}$ added and equilibrated at $37^{\circ} \mathrm{C}$ for $1 \mathrm{~h}$. The bacteria to be assayed were suspended and diluted in HS and added to the cells at an m.o.i. of 10 . After the bacteria were allowed to interact with the cells for $30 \mathrm{~min}$ at $37^{\circ} \mathrm{C}$ the wells were then washed with HS and incubated in HS plus $100 \mu$ g gentamicin $\mathrm{ml}^{-1}$ for $2 \mathrm{~h}$. After antibiotic treatment the cells were washed with HS, then lysed by incubation for $10 \mathrm{~min}$ in $1 \mathrm{ml}$ water followed by vigorous pipetting. After lysis, the number of intracellular bacteria was determined by plating for c.f.u. on BCYE. Entry levels were determined by calculating the percentage of the inoculum that became gentamicin-resistant over the course of the assay (i.e. entry=c.f.u. gentamicinresistant/c.f.u. inoculum). To correct for variation in levels of uptake between experiments, entry is reported relative to AA100 [i.e. percentage entry $=$ (entry test strain/entry AA100 $\times 100]$. Adhesion was tested in a similar manner to that for entry, except that bacteria were added to the cells, mixed and immediately washed three times to remove nonadherent bacteria prior to lysis.

Intracellular growth assays. Intracellular growth assays were carried out as described previously (Cirillo et al., 1997). Bacteria were added to a monolayer of $1.5 \times 10^{5}$ amoebae in 24-well tissue culture dishes at an m.o.i. of 0.5 and incubated at $37^{\circ} \mathrm{C}$ for $30 \mathrm{~min}$. The cells were washed three times with HS, incubated in HS plus $100 \mu$ gentamicin $\mathrm{ml}^{-1}$ for $2 \mathrm{~h}$, placed in fresh HS and lysed at various time points with water. Survival is expressed as the percentage of c.f.u. present at each time point as compared to time zero $(2 \cdot 5 \mathrm{~h})$.

Frequencies of lysosomal fusion. Lysosomes were stained and the frequency of fusion with the bacterial phagosome was determined by transmission electron microscopy, as described previously (Cirillo et al., 1997). After pre-labelling the amoebae with thorium dioxide (Polysciences) they were infected with the bacteria for $30 \mathrm{~min}$. The samples were then fixed and prepared for electron microscopy at various time points as described previously (Bowers \& Korn, 1968; Cirillo et al., 1997; Niszl \& Markus, 1989).

Lysosomes were stained for fluorescence microscopy with lucifer yellow (LY) as described by Bizal et al. (1991), Heinzen et al. (1996) and Swanson (1989). After pre-labelling the amoebae with $1 \mathrm{mg} \mathrm{LY} \mathrm{ml}^{-1}$ for $2 \mathrm{~h}$ the cells were washed with $\mathrm{HS}$ and incubated in HS for $1 \mathrm{~h}$ at $37^{\circ} \mathrm{C}$. L. pneumophila cells were pre-stained with rhodamine red (RhR) prior to infection in a similar manner to that previously described using fluorescein (Francis et al., 1993; Wiater et al., 1998). Basically, the bacteria were suspended in PBS plus $5 \mu \mathrm{g} \mathrm{RhR} \mathrm{ml}{ }^{-1}$, incubated at $37^{\circ} \mathrm{C}$ for $30 \mathrm{~min}$ and washed five times to remove unbound RhR. The RhR staining procedure did not affect bacterial viability or intracellular trafficking. Viability of the labelled bacteria was confirmed using the LIVE-DEAD assay (Molecular Probes) and by plating dilutions for c.f.u. on BCYE agar (Difco). The LY-labelled amoebae were infected with the bacteria for $30 \mathrm{~min}$, washed with HS and incubated in HS for various periods of time. At each time point the monolayers were fixed in $4 \%(\mathrm{v} / \mathrm{v})$ paraformaldehyde for $30 \mathrm{~min}$ and examined on a Nikon TE300 inverted microscope 
Table 1. Characteristics of Legionella strains

\begin{tabular}{|c|c|c|c|}
\hline Strain (isolate) & $\operatorname{rtx} A^{*}$ & Disease $†$ & Reference \\
\hline L. pneumophila sg 1 (130b) & + & + & Engleberg et al. (1984) \\
\hline L. pneumophila sg 1 (Allentown I) ATCC 43106 & + & + & Joly et al. (1986) \\
\hline L. pneumophila sg 1 (Camperdown 1) ATCC 43113 & + & + & Joly et al. (1986) \\
\hline L. pneumophila sg 1 (Benidorm 030 E) ATCC 43108 & + & + & Joly et al. (1986) \\
\hline L. pneumophila sg 1 (OLDA) ATCC 43109 & + & + & Joly et al. (1986) \\
\hline L. pneumophila sg 7 (Chicago 8) ATCC 33823 & + & + & Bibb et al. (1983) \\
\hline L. anisa (CH-47-C1) ATCC 35290 & - & - & Gorman et al. (1985) \\
\hline L. brunensis (441-1) ATCC 43878 & - & - & Wilkinson et al. (1988) \\
\hline L. feeleii sg 1 (WO-44C) ATCC 35072 & + & + & Herwaldt et al. (1984) \\
\hline L. longbeachae sg 2 (Tucker 1) ATCC 33484 & - & + & Bibb et al. (1981) \\
\hline L. gormanii (86A5796) ATCC 43769 & - & - & Morris et al. (1980) \\
\hline L. moravica (316-86) ATCC 43877 & - & - & Wilkinson et al. (1988) \\
\hline L. dumoffii (NY 23) ATCC 33279 & - & - & Brenner et al. (1980) \\
\hline L. sainthelensi (MSH-4) ATCC 35248 & - & - & Campbell et al. (1984) \\
\hline
\end{tabular}

* The presence of the $r t x A$ gene in the chromosome, as demonstrated by Southern analysis, is indicated by + and the absence by - .

† Strains that were directly isolated from diseased human lungs or strongly linked to disease (data exist showing that this isolate is the same as one directly isolated from diseased lungs) are indicated by + and environmental isolates that are not associated or only weakly (no data exist showing that this isolate is the same as one that causes disease) or rarely associated with disease in humans by - .

with fluorescein isothiocyanate and tetramethylrhodamine isothiocyanate filters. Dual images were captured using an Optronics charge-coupled device video camera for subsequent manual quantification of lysosomal fusion frequencies. Images were merged and adjusted for brightness and contrast using Adobe Photoshop version 5.5.

Cytotoxicity and pore formation. The standard lactate dehydrogenase (LDH) release cytotoxicity assay (Behl et al., 1994; Brander et al., 1993) was used in these studies as described previously (Cirillo et al., 2001). The procedure used was essentially as recommended by the manufacturer of the CytoTox96 Non-Radioactive Cytotoxicity Assay system (Promega). Serial dilutions were made of each bacterial strain at m.o.i.s of 500, 250, 100 and 10 in a final volume of $100 \mu \mathrm{l}$ for each assay using $2 \times 10^{4}$ amoebae. Appropriate numbers of cells for CytoTox96 assays were determined as suggested by the manufacturer (Promega). As a positive control for $100 \%$ cytotoxicity and the utility of this assay in amoebae, the cells were lysed with 9\% (v/v) Triton X-100 (Promega). The cells were incubated with the bacteria for $4 \mathrm{~h}$ at $37^{\circ} \mathrm{C}$ with $5 \%$ $(\mathrm{v} / \mathrm{v}) \mathrm{CO}_{2}$. Cytotoxicity readings were taken using an ELISA plate reader at $450 \mathrm{~nm}$. Percentage cytotoxicity was calculated as recommended by the manufacturer and corrected for small differences in the inocula used.

Formation of pores in host cells was assayed by ethidium bromide and acridine orange staining in exactly the same manner as described previously (Cirillo et al., 2001; Kirby et al., 1998; Zuckman et al., 1999) using A. castellanii cells. Stained coverslips were examined using a Nikon TE300 inverted microscope with fluorescein isothiocyanate and tetramethylrhodamine isothiocyanate filters. Dual images of multiple fields were captured using an Optronics chargecoupled device video camera and analysed in the same manner as described by Zuckman et al. (1999). Pore formation is expressed as the percentage of acridine-orange-stained cells that also stain with ethidium bromide resulting from incorporation of this dye into chromosomal DNA due to increased permeability of the host cell. All cells were stained with acridine orange since, unlike ethidium bromide, acridine orange readily crosses membranes of eukaryotic cells. As a positive control, amoebae were first fixed with formaldehyde and then permeabilized with methanol prior to staining. Under these conditions, all amoebae stained well with both ethidium bromide and acridine orange.

Southern analyses and colony hybridization. Probes were labelled by PCR with digoxigenin using the methods suggested by the manufacturer of the Genius System (Boehringer Mannheim). Membranes were prepared by the suggested methods for both colony hybridization and Southern analysis. Hybridization and washes were carried out at several different stringencies to ensure that the data obtained were not due to sequence divergence between Legionella species. Experiments generating the data shown were carried out under low stringency hybridization conditions. The probe for the $r t x A$ gene was prepared by PCR using oligo $1\left(5^{\prime}\right.$ CTGATGCTGCTACGGAACAC-3') and oligo 2 (5'-CCGCAGTCATTACACCTGCG-3'). This resulted in the production of a $542 \mathrm{bp}$ fragment within the $r t x A$ gene. The probe for the mip gene was also prepared by PCR using oligo $3\left(5^{\prime}\right.$ GCAGCTGTTATGGGGCTTGC-3') and oligo 4 (5'-GGCAATACAACAACGCCTGG-3'), producing a 352 bp fragment within the mip gene.

Statistical analyses. All experiments were carried out in triplicate and repeated at least twice. Significance of the results was analysed using ANOVA. Values of $P<0.05$ were considered significant.

\section{RESULTS}

\section{Correlation of $r$ txA with disease}

The $r t x A$ gene has previously been associated with the ability of Legionella to cause disease in mice (Cirillo et al., 2001). However, it remains unclear whether $r t x A$ is 


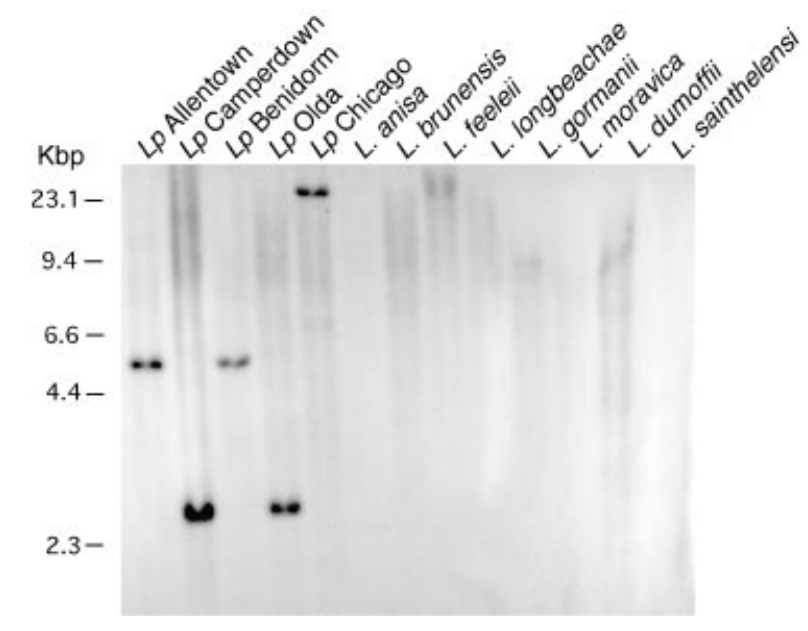

Fig. 1. Southern analysis of different Legionella isolates. All lanes are EcoRI digests of total chromosomal DNA probed with a $542 \mathrm{bp}$ internal fragment of the Legionella $r t x A$ gene. This blot was hybridized under low stringency conditions. The positions of $\lambda$ phage DNA size standards cut with HindIII are shown on the left. Lp, Legionella pneumophila.

of particular importance for pathogenesis in humans or is required for survival and replication of Legionella in the environment. Predominance in the environment is likely to correlate with the ability of different Legionella to interact positively with water-borne protozoa, including amoebae. To better evaluate the importance of the rtxA gene in human disease and survival in the environment, we examined whether there is a correlation between the presence of this gene and the strength of association of different Legionella isolates with human disease. The presence of the $r t x A$ gene in 14 Legionella isolates was determined by Southern analysis (Fig. 1). The approximately $5 \mathrm{kbp}$ fragment visible in $L$. pneumophila Allentown and Benidorm corresponds to the size of fragment observed in AA100 (data not shown). Under the same hybridization conditions, a probe from the mip gene hybridizes to chromosomal DNA from all of these species, suggesting that sequence divergence alone is not responsible for the inability to detect $r t x A$ (data not shown). Differences in signal intensity by Southern analysis were observed in species other than L. pneumophila, suggesting that, as expected due to their more distant relationship to AA100, greater DNA sequence divergence exists within the $r t x A$ gene in these species. Since nearly all Legionella species are thought to be able to cause disease at some frequency, we used stringent criteria to evaluate whether the isolates tested are strongly or weakly associated with disease in our studies. Thus, if an isolate was directly obtained from post-mortem tissue or sputum from a clinically ill individual or there was documented evidence that it is the same as that causing disease, the isolate was considered strongly associated with disease. If, however, the isolate was obtained from an environmental source, even if it was the same species as that observed to cause
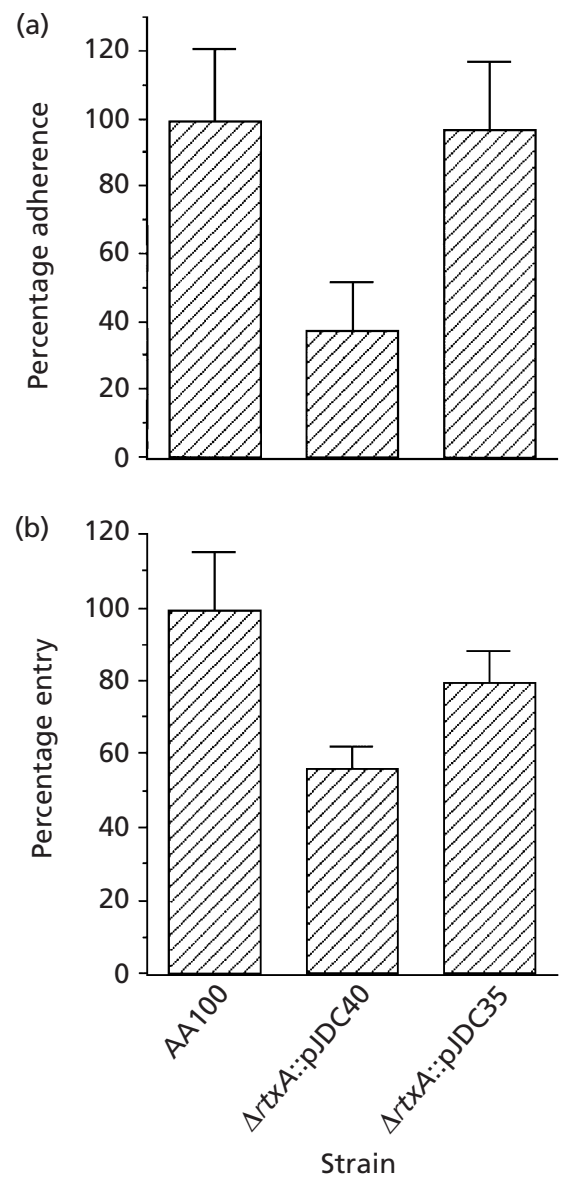

Fig. 2. The ability of the wild-type $L$. pneumophila strain AA100, $\triangle r t x A$ mutant ( $\triangle r t x A:: p J D C 40)$ and complemented clone ( $\triangle r t x A:: p J D C 35)$ to adhere to (a) and enter into (b) Acanthamoeba castellanii. Data points and error bars represent the means of triplicate samples and their standard deviations, respectively. The adherence and entry levels of wild-type $L$. pneumophila strain AA100 are arbitrarily set to $100 \%$. All experiments were performed at least three times.

disease in humans, or the species of the isolate only rarely causes disease in humans, we considered the isolate to be only weakly associated with human disease. Using these criteria, eight of the isolates examined had a strong association with disease and, of these, seven $(88 \%)$ also had the $r t x A$ gene (Table 1). Furthermore, none of the isolates that are only weakly or rarely associated with disease in humans has the $\operatorname{rtx} A$ gene. Thus, the presence of the $r t x A$ gene correlates $(P<0 \cdot 01)$ with the ability of Legionella to cause disease in humans.

\section{L. pneumophila does not cause cytotoxicity or pore formation in amoebae}

The prevalence of certain Legionella strains in human disease may be the result of higher virulence, a selective advantage in the environment or a combination of these features. As a measure of the importance of $r t x A$ in the 


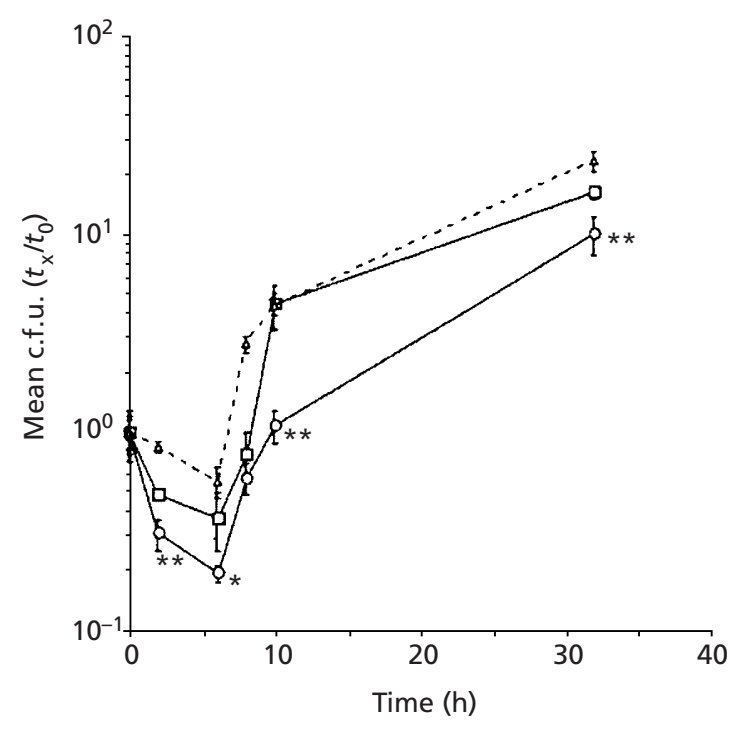

Fig. 3. Growth of wild-type L. pneumophila strain AA100 ( $\square$ ), $\triangle r t x A$ mutant $(\triangle r t x A::$ pJDC40, $\bigcirc)$ and complemented clone $(\triangle r t x A:: p J D C 35, \triangle)$ in amoebae. All data are expressed relative to time zero $\left(t_{0}=2.5 \mathrm{~h}\right)$. * $(P<0.05)$ and $* *(P<0.01)$ indicate data points significantly different from wild-type. Data points and error bars represent the means of quadruplicate samples and their standard deviations, respectively. All experiments were performed at least three times.

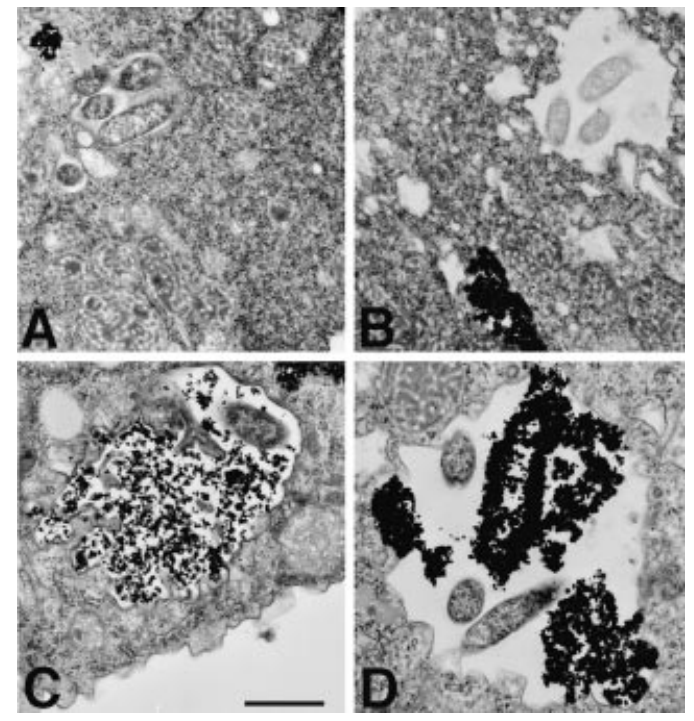

Fig. 4. Fusion of lysosomes containing thorium (electron-dense granules) with the $L$. pneumophila strain AA100 (A, C) and $\Delta r t x A$ mutant $(B, D)$ vacuole 120 min after entry. Examples of unfused vacuoles are shown for the wild-type (A) and $r t x A$ mutant (B). Fused vacuoles are infrequently observed for the wild-type strain AA100 (C), whereas approximately half of the $r t x A$ mutant vacuoles contain thoria (D). Bar, $1 \mu \mathrm{m}$.

survival of L. pneumophila in the environment, we examined the effects of this gene on the interaction of $L$. pneumophila with A. castellanii. An in-frame deletion
Table 2. Fusion of Legionella vacuole with lysosomes by electron microscopy

\begin{tabular}{|c|c|c|c|}
\hline \multirow{2}{*}{$\begin{array}{l}\text { Time after } \\
\text { entry ( } \mathrm{min})\end{array}$} & \multicolumn{3}{|c|}{ Percentage fusion* } \\
\hline & AA100 & $\Delta r t x A:: \mathrm{pJDC} 40$ & $\operatorname{vrtx} A::$ pJDC35 \\
\hline 15 & $27 \cdot 9 \pm 2 \cdot 4$ & $32 \cdot 8 \pm 1 \cdot 8$ & $25 \cdot 1 \pm 1 \cdot 6$ \\
\hline 60 & $24 \cdot 2 \pm 1 \cdot 3$ & $45 \cdot 1 \pm 0 \cdot 8 \dagger$ & $23 \cdot 9 \pm 1 \cdot 2$ \\
\hline 120 & $21 \cdot 2 \pm 2 \cdot 4$ & $54 \cdot 7 \pm 2 \cdot 0 \dagger$ & $20 \cdot 5 \pm 2 \cdot 1$ \\
\hline \multicolumn{4}{|c|}{$\begin{array}{l}\text { *Percentage of wild-type (AA100), } \Delta r t x A \text { mutant } \\
(\Delta r t x A:: \text { pJDC40) and complemented mutant }(\Delta r t x A:: \text { JDC } 35) \\
\text { L. pneumophila vacuoles containing thorium. Results are the } \\
\text { mean values } \pm \text { sE for three counts of vacuoles within at least } 50 \\
\text { amoebae on different sections of the same preparation. }\end{array}$} \\
\hline \multicolumn{4}{|c|}{$\begin{array}{l}\text { † Significantly different }(P<0 \cdot 01) \text { from the result for wild-type } L \text {. } \\
\text { pneumophila. }\end{array}$} \\
\hline
\end{tabular}

of the L. pneumophila rtxA gene transformed with a single-copy construct that complements the $\operatorname{rtx} A \mathrm{mu}-$ tation (pJDC35) or the same construct without rtxA (pJDC40) were used for these studies. All of the strains used in the current study, as well as their phenotypes in mammalian cells, have been described previously (Cirillo et al., 2001). In contrast to previous results with murine and human macrophages (Cirillo et al., 2001; Kirby et al., 1998), no cytotoxicity or pore formation was observed after incubation of wild-type $L$. pneumophila or the rtxA mutant with A. castellanii (data not shown). To ensure that the conditions of the experiment were not responsible for this negative result, we examined bacteria to host-cell ratios as high as 1000: 1 , as well as co-incubation periods from 1 to $6 \mathrm{~h}$. None of these conditions resulted in significant cytotoxicity or pore formation (data not shown). In addition, the positive controls of Triton-X-100-killed amoebae (cytotoxicity) and permeabilization with methanol after fixation followed by staining for fluorescent microscopy (pore formation) demonstrated that these assay methods work well in amoebae (data not shown). Thus, $L$. pneumophila does not cause cytotoxicity or pore formation in A. castellanii.

\section{rtxA affects adherence and entry}

Since the L. pneumophila rtxA gene plays a role in entry into human cells (Cirillo et al., 2001, 2000), we examined its role in adherence and entry into A. castellanii (Fig. 2). The L. pneumophila rtxA mutation reduced adherence $(P<0.03)$ and entry $(P<0.02)$ to amoebae by approximately $50 \%$ compared to wild-type. Levels of adherence that were not significantly different than wild-type L. pneumophila were obtained in the rtxA mutant carrying a complementing construct, pJDC35. All strains were tested for sensitivity to assay conditions such as osmotic lysis, culture medium and serum. No significant differences in sensitivity to these conditions were observed with the strains used. These data suggest that, similar to its role in mammalian cells, $r t x A$ is 

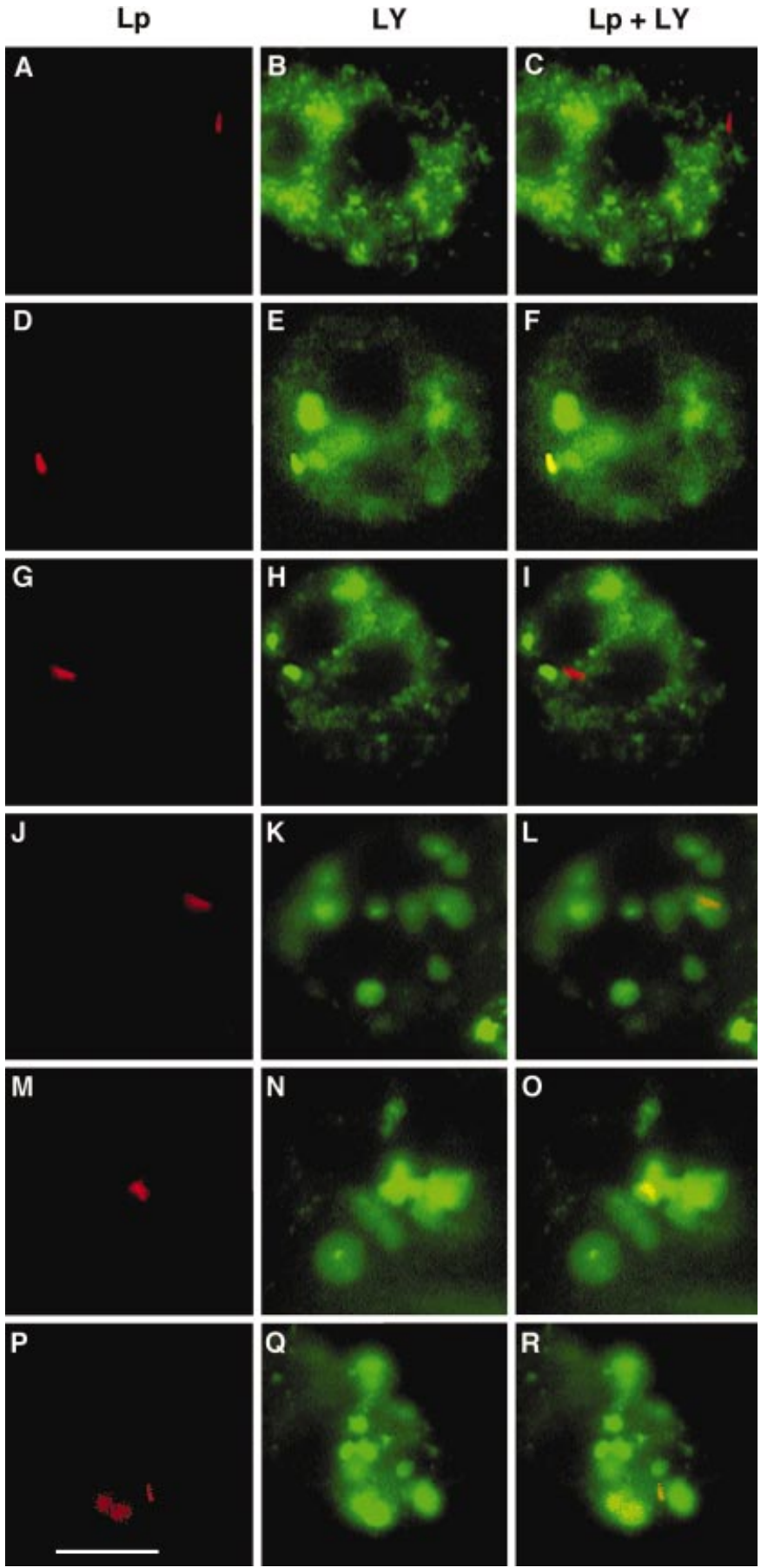
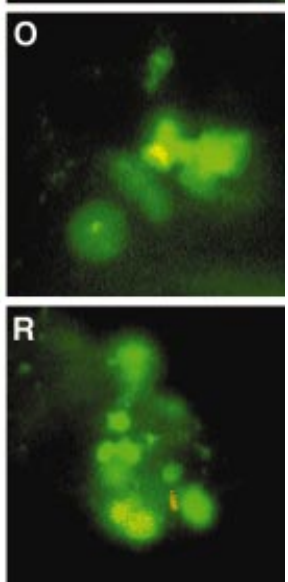

Fig. 5. Fusion of lysosomes (green) containing LY with the L. pneumophila (red) vacuoles for strains AA100 (A-F), $\Delta r t x A(G-L)$ and the avirulent $\psi$ lp55 (M-R). All panels shown are $150 \mathrm{~min}$ after infection of the amoebae. Split and merged $(L p+L Y)$ images are shown using RhR and LY filter sets. The red colour indicates RhR-stained bacteria, which appear as rods (A, D, G, J) or, when they are presumably partially degraded, as diffuse red-staining regions $(M, P)$. The green colour indicates lysosomes stained with LY. When the bacterial vacuole colocalizes with lysosomes, a yellow colour results in the merged images $(F, L, O, R)$. Fused vacuoles are infrequently observed for the wild-type strain AA100 (F), whereas approximately half of the $r t x A$ mutant (L) and the majority of the $\psi / p 55(\mathrm{O}, \mathrm{R})$ vacuoles co-localize with LY. Bar, $10 \mu \mathrm{m}$. involved in adherence to and entry into amoebae in environmental reservoirs.

\section{$r t x A$ plays a role in intracellular survival}

Since $r t x A$ plays a role in entry by L. pneumophila into amoebae it may also impact subsequent intracellular events. To evaluate this possibility, we compared the ability of the $\operatorname{rtx} A$ mutant to survive and replicate in amoebae with wild-type L. pneumophila (Fig. 3). The $\operatorname{rtx} A$ mutant did not survive as well as wild-type
$(P<0.01)$ for the majority of time points through the first $32 \mathrm{~h}$ after entry. Interestingly, the $r t x A$ mutant complemented with a plasmid-borne copy of the gene displayed enhanced intracellular survival. Since $r t x A$ does not affect growth in laboratory medium (Cirillo et al., 2001), its role in survival is specific to the intracellular growth environment. The $r t x A$ mutant was killed $(80 \%)$ much more efficiently than wild-type $(62 \%)$ during the first $6 \mathrm{~h}$ in amoebae. The subsequent rate of intracellular replication was the same as wild-type, with the $r t x A$ mutant increasing 50-fold and wild-type 45 -fold by $32 \mathrm{~h}$. 
Table 3. Fusion of Legionella vacuole with lysosomes by fluorescent microscopy

\begin{tabular}{|c|c|c|c|c|}
\hline \multirow{2}{*}{$\begin{array}{l}\text { Time after } \\
\text { entry }(\mathrm{min})\end{array}$} & \multicolumn{4}{|c|}{ Percentage fusion* } \\
\hline & AA100 & $\Delta r t x A:: p J D C 40$ & $\Delta r t x A:: p J D C 35$ & $\psi \operatorname{lp55}$ \\
\hline 30 & $30 \cdot 0 \pm 1 \cdot 2$ & $35 \cdot 8 \pm 2 \cdot 4 \dagger$ & $28 \cdot 7 \pm 0 \cdot 7$ & $46 \cdot 6 \pm 1 \cdot 4 \neq$ \\
\hline 90 & $22 \cdot 8 \pm 0 \cdot 3$ & $43 \cdot 0 \pm 1 \cdot 2 \neq$ & $22 \cdot 9 \pm 1 \cdot 0$ & $78 \cdot 6 \pm 1 \cdot 2 \neq$ \\
\hline 150 & $24 \cdot 0 \pm 1 \cdot 0$ & $43 \cdot 7 \pm 0 \cdot 9 \neq$ & $23 \cdot 3 \pm 0 \cdot 9$ & $78 \cdot 1 \pm 3 \cdot 0 \neq$ \\
\hline
\end{tabular}

*Percentage of wild-type (AA100), $\Delta r t x A$ mutant ( $r r t x A::$ pJDC40), complemented mutant $(\Delta r t x A::$ pJDC35) and avirulent mutant $(\psi \mathrm{lp} 55)$ L. pneumophila vacuoles containing LY. Results are the mean values $\pm \mathrm{SE}$ for three counts of vacuoles within at least 50 amoebae from different samples.

† Significantly different $(P<0 \cdot 05)$ from the result for wild-type L. pneumophila.

$\ddagger$ Significantly different $(P<0 \cdot 01)$ from the result for wild-type L. pneumophila.

These data suggest that $r t x A$ is primarily involved in the early steps of the interaction of L. pneumophila with amoebae.

\section{Role of $r t x A$ in intracellular trafficking}

One potential mechanism by which a gene that affects entry might impact initial intracellular survival would be through changes in trafficking of the bacterial vacuole resulting from signal transduction during phagocytosis. L. pneumophila normally has the ability to inhibit lysosomal fusion in macrophages (Horwitz \& Maxfield, 1984) and amoebae (Bozue \& Johnson, 1996). We examined the frequencies of lysosomal fusion with the wild-type and $r t x A$ mutant bacterial vacuole by electron microscopy using thorium dioxide (Fig. 4), an electrondense colloidal marker that is retained within secondary lysosomes (Armstrong \& Hart, 1971). Vacuoles containing the rtxA mutant fused with lysosomes at a significantly higher rate $(P<0 \cdot 01)$ than wild-type $L$. pneumophila (Table 2). Although there was no significant difference in the frequencies of fusion between the $r t x A$ mutant and wild-type at $15 \mathrm{~min}$, the difference was nearly twofold by $1 \mathrm{~h}$ hour and more than twofold by $2 \mathrm{~h}$ after entry.

To confirm this result using a different method we prelabelled the amoebal lysosomes with LY. This marker has been used extensively to label secondary lysosomes in macrophages and other eukaryotic cells (Bizal et al., 1991; Heinzen et al., 1996; McClure \& Schiller, 1996; Straub et al., 1997; Swanson, 1989). This label allowed clear differentiation between fused and unfused bacterial vacuoles (Fig. 5). In addition, similar frequencies of lysosomal fusion were obtained for wildtype L. pneumophila to those by electron microscopy (Table 3). The laboratory-passaged avirulent AA100 mutant $\psi 1 \mathrm{lp} 55$ displayed the expected high frequencies of lysosomal fusion (78\%) observed previously for similar mutants (Roy et al., 1998; Swanson \& Isberg, 1996). We found that, even as early as $30 \mathrm{~min}$ after entry, the $r t x \mathrm{~A}$ mutant fused with LY-labelled lysosomes at a significantly higher level $(P<0.05)$ than wild-type L. pneu- mophila. The difference in the frequencies of lysosomal fusion between the $r t x A$ mutant and wild-type was much more pronounced by $90 \mathrm{~min}(P<0 \cdot 01)$. These data confirm that the L. pneumophila rtxA gene plays a role in intracellular trafficking in amoebae.

\section{DISCUSSION}

We have found that the L. pneumophila rtxA gene is not present in all Legionella species and that its presence correlates with the ability to cause disease in humans. This observation, along with previous studies demonstrating that this gene plays an important role in virulence (Cirillo et al., 2001), has helped to fulfil 'molecular Koch's postulates' for $r t x A$, supporting the conclusion that this gene plays a role in disease (Falkow, 1988). There are three criteria required to fulfil these postulates. First, specific inactivation of the rtxA gene leads to a measurable loss of virulence in mice (Cirillo et al., 2001). Second, complementation of the mutated rtxA gene leads to restoration of virulence in mice (Cirillo et al., 2001). Third, the $r t x A$ gene is associated with pathogenic members of the genus, as demonstrated in the current study. This represents an important step in our understanding of the molecular aspects of Legionnaires' disease. However, although $r t x A$ fits the criteria for an important role in pathogenesis, the primary function(s) of this gene both during disease and in the environment are not fully understood.

Similar to data obtained in mammalian cells (Cirillo et al., 2001, 2000), the rtxA gene affects adherence and entry into amoebae. The mechanism by which $r t x A$ affects adherence and entry in mammalian cells is not known, though it may be the result of the ability of RTX proteins to bind to $\beta_{2}$ integrin receptors (Ambagala et al., 1999; Lally et al., 1997). Although receptors analogous to integrins have not yet been identified in Acanthamoeba, they have been identified in the amoebae Hartmannella (Venkataraman et al., 1997) and Entamoeba (Adams et al., 1993; Vines et al., 1998) as well as in coral and sponges (Brower et al., 1997). These observations suggest that integrin receptors are highly 
conserved throughout all eukaryotic cells. This conclusion is supported by evidence that the Entamoeba receptor shares an immunologically cross-reactive epitope with human $\beta_{2}$ integrins (Adams et al., 1993) and contains a $\beta_{2}$ integrin motif in its cytoplasmic domain (Vines et al., 1998). Thus, it remains possible that a similar receptor is available for binding to L. pneumophila via RtxA in both macrophages and amoebae. Considering that a similar receptor may be utilized, it is surprising that no pore formation or cytotoxicity is observed in Acanthamoeba, in contrast to macrophages. Since environmental amoebae are most likely the natural host for L. pneumophila, these data suggest that pore formation and cytotoxicity are not the primary roles of $r t x A$ in bacterial-host-cell interactions. Several other potential roles in pathogenesis have been suggested for RTX proteins from other bacteria, including colonization (Goodwin \& Weiss, 1990), immune modulation (Bhakdi et al., 1990; Scheffer et al., 1985) and inhibition of superoxide production (Keane et al., 1987). Therefore, closer examination of the role of the L. pneumophila rtxA gene in adherence, entry and intracellular survival are likely to provide a better understanding of its primary role in Legionnaires' disease and may lead to insight into alternate functions of RTX proteins from other bacteria.

It is possible that the effects of the $r t x A$ mutant on intracellular survival are directly related to the role of $r t x A$ in adherence or entry, though the defect in trafficking is less pronounced than the salt-resistant mutant $\psi$ lp55. This concept would suggest that proper intracellular trafficking of L. pneumophila, and thereby survival, are the result of signalling events that occur during uptake. However, in our own and other studies (Joshi et al., 2001; Roy et al., 1998), little difference has been found between the trafficking of L. pneumophila mutants and wild-type during the first 5-10 min following entry. If signalling during uptake is involved, it has long-lasting effects upon trafficking of the bacterial phagosome. It is equally possible that RtxA is a multifunctional protein, binding a host-cell receptor affecting adherence and entry, as well as subsequently inhibiting lysosomal fusion. There are two primary mechanisms by which RtxA might inhibit lysosomal fusion independent of events associated with entry. First, it may be that the formation of pores caused by RtxA in the vacuole itself prevents proper docking of lysosomes, preventing fusion. Second, an as yet unidentified activity of RtxA modifies the vacuole or other host-cell component that is involved in trafficking. It remains to be determined whether RtxA is one of the proteins secreted by the $d o t / i c m$ secretion apparatus previously implicated in the intracellular trafficking of L. pneumophila (Berger et al., 1994; Swanson \& Isberg, 1996). Based on the frequencies of lysosomal fusion observed (40-50\% with the $r t x A$ mutant and $80-90 \%$ with a $\operatorname{dot} A$ mutant), there must be additional factors involved in the inhibition of lysosomal fusion other than RtxA. Our studies were carried out in amoebae rather than the human or murine monocytes used for the evaluation of $\operatorname{dot} A$ mutants. However, similar results were obtained by our laboratory for frequencies of lysosomal fusion using the $r t x A$ mutant in murine macrophages (L. Yan \& J. D. Cirillo, unpublished observations). The fact that other factors are likely to be involved in the prevention of lysosomal fusion by L. pneumophila suggests the importance of further studies in this area.

The rtxA gene plays a role in the ability of $L$. pneumophila to survive in A. castellanii. The impact of the $r t x A$ mutation on intracellular survival is, however, relatively small. One possible explanation for this observation might be that the wild-type bacteria, when grown under standard laboratory conditions, do not express $r t x A$ optimally and thus the absence of $r t x A$ only results in a limited impact on survival. The fact that complementation of the $r \operatorname{txA}$ mutant with a plasmid enhances intracellular survival supports this conclusion, since these bacteria are likely to express the $r t x A$ gene at higher levels than wild-type due to copy number effects. Since several of the species that did not have this gene according to Southern analysis can still cause disease in animals and the $r t x A$ mutant still replicates in human macrophages, albeit poorly (Cirillo et al., 2001), the $r t x A$ gene is probably not absolutely required for pathogenesis. It is also likely that, similar to other intracellular pathogens, including Salmonella, Shigella and Listeria, the ability of L. pneumophila to survive and replicate intracellularly is multi-factorial. In the case of Salmonella, nearly $3 \%$ of the genome is thought to be required for the ability to survive intracellularly (P. I. Fields et al., 1986). Application of this model to $L$. pneumophila would suggest that between 100 and 150 genes could be involved in the ability to survive and replicate in macrophages. Thus, one would expect that few of these genes would completely debilitate $L$. pneumophila intracellularly. Mutations in most genes, other than those required for metabolism and biosynthesis, would result in only partial and potentially subtle intracellular defects.

These observations suggest that careful evaluation of potential virulence determinants using both laboratory and animal models of infection in both susceptible and resistant hosts is necessary to allow identification of the important factors involved in pathogenesis by L. pneumophila. The $\Delta r t x A$ mutant should greatly facilitate further investigation of the host-cell receptors, signalling pathways and intracellular trafficking mechanisms of $L$. pneumophila. Further studies are needed, in particular to determine whether the mechanism of entry involving RtxA is responsible for subsequent intracellular events or whether RtxA is a multi-functional protein having the ability to bind host-cell receptors as well as independently preventing lysosomal fusion. In addition to its role in virulence in mammals (Cirillo et al., 2001), the rtxA gene plays an important role in the ability of $L$. pneumophila to infect amoebae. These observations suggest that the $r t x A$ gene is at least partially responsible for the high percentage of Legionnaires' pneumonias caused by and the predominance in environmental 
isolates of L. pneumophila, as compared to other Legionella species.

\section{ACKNOWLEDGEMENTS}

This work was supported by grant AI40165 from the National Institutes of Health.

\section{REFERENCES}

Abu Kwaik, Y. (1996). The phagosome containing Legionella pneumophila within the protozoan Hartmannella vermiformis is surrounded by the rough endoplasmic reticulum. Appl Environ Microbiol 62, 2022-2028.

Adams, S. A., Robson, S. C., Gathiram, V., Jackson, T. F., Pillay, T. S., Kirsch, R. E. \& Makgoba, M. W. (1993). Immunological similarity between the $170 \mathrm{kD}$ amoebic adherence glycoprotein and human beta 2 integrins. Lancet 341, 17-19.

Allen, P. G. \& Dawidowicz, E. A. (1990a). Phagocytosis in Acanthamoeba: I. A mannose receptor is responsible for the binding and phagocytosis of yeast. J Cell Physiol 145, 508-513.

Allen, P. G. \& Dawidowicz, E. A. (1990b). Phagocytosis in Acanthamoeba: II. Soluble and insoluble mannose-rich ligands stimulate phosphoinositide metabolism. J Cell Physiol 145, 514-521.

Ambagala, T. C., Ambagala, A. P. N. \& Srikumaran, S. (1999). The leukotoxin of Pasteurella haemolytica binds to $\beta 2$ integrins on bovine leukocytes. FEMS Microbiol Lett 179, 161-167.

Anand, C. M., Skinner, A. R., Malic, A. \& Kurtz, J. B. (1983). Interaction of L. pneumophila and a free living amoeba (Acanthamoeba palestinensis). J Hyg 91, 167-178.

Armstrong, J. A. \& Hart, P. D. A. (1971). Response of cultured macrophages to Mycobacterium tuberculosis with observations on fusion of lysosomes with phagosomes. J Exp Med 134, 713-740.

Behl, C., Davis, J. B., Lesley, R. \& Schubert, D. (1994). Hydrogen peroxide mediates amyloid beta protein toxicity. Cell 77, 817-827.

Berger, K. H., Merriam, J. J. \& Isberg, R. R. (1994). Altered intracellular targeting properties associated with mutations in the Legionella pneumophila dotA gene. Mol Microbiol 14, 809-822.

Bhakdi, S., Muhly, M., Korom, S. \& Schmidt, G. (1990). Effects of Escherichia coli hemolysin on human monocytes. Cytocidal action and stimulation of interleukin 1 release. J Clin Invest $\mathbf{8 5}$, 1746-1753.

Bibb, W. F., Sorg, R. J., Thomason, B. M., Hicklin, M. D., Steigerwalt, A. G., Brenner, D. J. \& Wulf, M. R. (1981). Recognition of a second serogroup of Legionella longbeachae. J Clin Microbiol 14, 674-677.

Bibb, W. F., Arnow, P. M., Dellinger, D. L. \& Perryman, S. R. (1983). Isolation and characterization of a seventh serogroup of Legionella pneumophila. J Clin Microbiol 17, 346-348.

Bizal, C. L., Butler, J. P., Feldman, H. A. \& Valberg, P. A. (1991). Kinetics of phagocytosis and phagosome-lysosome fusion in hamster lung and peritoneal macrophages. J Leukoc Biol 50, 229-239.

Bowers, B. \& Korn, E. D. (1968). The fine structure of Acanthamoeba castellanii. I. The trophozoite. J Cell Biol 39, 95-111.

Bozue, J. A. \& Johnson, W. (1996). Interaction of Legionella pneumophila with Acanthamoeba castellanii: Uptake by coiling phagocytosis and inhibition of phagosome-lysosome fusion. Infect Immun 64, 668-673.

Brander, C., Wyss-Coray, T., Mauri, D., Bettens, F. \& Pichler, W. J.
(1993). Carrier-mediated uptake and presentation of a major histocompatibility complex class I-restricted peptide. Eur J Immunol 23, 3217-3223.

Brenner, D. J., Steigerwalt, A. G., Gorman, G. W. \& 8 other authors (1980). Legionella bozemanii sp. nov. and Legionella dumoffii sp. nov.: classification of two additional species of Legionella associated with human pneumonia. Curr Microbiol 4, 111-116.

Brieland, J., McClain, M., Heath, L., Chrisp, C., Huffnagle, G., LeGendre, M., Hurley, M., Fantone, J. \& Engleberg, C. (1996). Coinoculation with Hartmannella vermiformis enhances replicative Legionella pneumophila lung infection in a murine model of Legionnaires' disease. Infect Immun 64, 2449-2456.

Brieland, J., McClain, M., LeGendre, M. \& Engleberg, C. (1997a). Intrapulmonary Hartmannella vermiformis : a potential niche for Legionella pneumophila replication in a murine model of legionellosis. Infect Immun 65, 4892-4896.

Brieland, J. K., Fantone, J. C., Remick, D. G., LeGendre, M., McClain, M. \& Engleberg, N. C. (1997b). The role of Legionella pneumophila-infected Hartmannella vermiformis as an infectious particle in a murine model of Legionnaires' disease. Infect Immun 65, 5330-5333.

Brower, D. L., Brower, S. M., Hayward, D. C. \& Ball, E. E. (1997). Molecular evolution of integrins: Genes encoding integrin $\beta$ subunits from a coral and a sponge. Proc Natl Acad Sci US A 94, 9182-9187.

Brown, R. C., Bass, H. \& Coombs, J. P. (1975). Carbohydrate binding proteins involved in phagocytosis by Acanthamoeba. Nature 254, 434-435.

Campbell, J., Bibb, W. F., Lambert, M. A., Eng, S., Steigerwalt, A. G., Allard, J., Moss, C. W. \& Brenner, D. J. (1984). Legionella sainthelensi: a new species of Legionella isolated from water near Mt. St. Helens. Appl Environ Microbiol 47, 369-373.

Cianciotto, N. P. \& Fields, B. S. (1992). Legionella pneumophila mip gene potentiates intracellular infection of protozoa and human macrophages. Proc Natl Acad Sci U S A 89, 5188-5191.

Cirillo, J. D., Falkow, S. \& Tompkins, L. S. (1994). Growth of Legionella pneumophila in Acanthamoeba castellanii enhances invasion. Infect Immun 62, 3254-3261.

Cirillo, J. D., Falkow, S., Tompkins, L. S. \& Bermudez, L. E. (1997). Interaction of Mycobacterium avium with environmental amoebae enhances virulence. Infect Immun 65, 3759-3767.

Cirillo, J. D., Cirillo, S. L. G., Yan, L., Bermudez, L. E., Falkow, S. \& Tompkins, L. S. (1999). Intracellular growth in Acanthamoeba castellanii affects monocyte entry mechanisms and enhances virulence of Legionella pneumophila. Infect Immun 67, 4427-4434.

Cirillo, S. L. G., Lum, J. \& Cirillo, J. D. (2000). Identification of novel loci involved in entry by Legionella pneumophila. Microbiology 146, 1345-1359.

Cirillo, S. L. G., Bermudez, L. E., El-Etr, S. H., Duhamel, G. E. \& Cirillo, J. D. (2001). Legionella pneumophila entry gene $r t x A$ is involved in virulence. Infect Immun 69, 508-517.

Davies, B. \& Edwards, S. W. (1991). Chemiluminescence and superoxide production in Acanthamoeba castellanii: free radicals generated during oxidative stress. J Gen Microbiol 137, 1021-1027.

Davies, B., Chattings, L. S. \& Edwards, S. W. (1991). Superoxide generation during phagocytosis by Acanthamoeba castellanii: similarities to the respiratory burst of immune phagocytes. J Gen Microbiol 137, 705-710.

Davis, G. S., Winn, W. C., Jr., Gump, D. W. \& Beaty, H. N. (1983). 
The kinetics of early inflammatory events during experimental pneumonia due to Legionella pneumophila in guinea pigs. J Infect Dis 148, 823-825.

Edelstein, P. H. (1981). Improved semiselective medium for isolation of Legionella pneumophila from contaminated clinical and environmental specimens. J Clin Microbiol 14, 298-303.

Engleberg, N. C., Drutz, D. J. \& Eisenstein, B. I. (1984). Cloning and expression of Legionella pneumophila antigens in Escherichia coli. Infect Immun 44, 222-227.

Falkow, S. (1988). Molecular Koch's postulates applied to microbial pathogenicity. Rev Infect Dis 10, S274-S276.

Fields, B. S., Barbaree, J. M., Shotts, E. B., Jr., Feeley, J. C., Morrill, W. E., Sanden, G. N. \& Dykstra, M. J. (1986). Comparison of guinea pig and protozoan models for determining virulence of Legionella species. Infect Immun 53, 553-559.

Fields, P. I., Swanson, R. V., Haidaris, C. G. \& Heffron, F. (1986). Mutants of Salmonella typhimurium that cannot survive within the macrophage are avirulent. Proc Natl Acad Sci USA 83, 5189-5193.

Fliermans, C. B., Cherry, W. B., Orrison, L. H., Smith, S. J., Tison, D. L. \& Pope, D. H. (1981). Ecological distribution of Legionella pneumophila. Appl Environ Microbiol 41, 9-16.

Francis, C. L., Ryan, T. A., Jones, B. D., Smith, S. J. \& Falkow, S. (1993). Ruffles induced by Salmonella and other stimuli direct macropinocytosis of bacteria. Nature 364, 639-642.

Gao, L. Y., Harb, O. S. \& Abu Kwaik, Y. (1997). Utilization of similar mechanisms by Legionella pneumophila to parasitize two evolutionarily distant host cells, mammalian macrophages and protozoa. Infect Immun 65, 4738-4746.

Goodwin, M. S. \& Weiss, A. A. (1990). Adenylate cyclase toxin is critical for colonization and pertussis toxin is critical for lethal infection by Bordetella pertussis in infant mice. Infect Immun $\mathbf{5 8}$, 3445-3447.

Gorman, G. W., Feeley, J. C., Steigerwalt, A., Edelstein, P. H., Moss, C. W. \& Brenner, D. J. (1985). Legionella anisa: a new species of Legionella isolated from potable waters and a cooling tower. Appl Environ Microbiol 49, 305-309.

Heinzen, R. A., Scidmore, M. A. \& Rockey, D. D. (1996). Differential interaction with endocytic and exocytic pathways distinguish parasitophorous vacuoles of Coxiella burnettii and Chlamydia trachomatis. Infect Immun 64, 796-809.

Henke, M. \& Seidel, K. M. (1986). Association between Legionella pneumophila and amoebae in water. Isr J Med Sci 22, 690-695.

Herwaldt, L. A., Gorman, G. W., McGrath, T. \& 12 other authors (1984). A new Legionella species, Legionella feeleii species nova, causes Pontiac fever in an automobile plant. Ann Intern Med $\mathbf{1 0 0}$, 333-338.

Horwitz, M. A. (1983). Formation of a novel phagosome by the Legionnaires' disease bacterium (Legionella pneumophila) in human monocytes. J Exp Med 158, 1319-1331.

Horwitz, M. A. (1984). Phagocytosis of the Legionnaires' disease bacterium (Legionella pneumophila) occurs by a novel mechanism: engulfment within a pseudopod coil. Cell 36, 27-33.

Horwitz, M. A. \& Maxfield, F. R. (1984). Legionella pneumophila inhibits acidification of its phagosome in human monocytes. J Cell Biol 99, 1936-1943.

Joly, J. R., McKinney, R. M., Tobin, J. O., Bibb, W. F., Watkins, I. D. \& Ramsay, D. (1986). Development of a standardized subgrouping scheme for Legionella pneumophila serogroup 1 using monoclonal antibodies. J Clin Microbiol 23, 768-771.

Joshi, A. D., Sturgill-Koszycki, S. \& Swanson, M. S. (2001).
Evidence that Dot-dependent and -independent factors isolate the Legionella pneumophila phagosome from the endocytic network in mouse macrophages. Cell Microbiol 3, 99-114.

Keane, W. F., Welch, R., Gekker, G. \& Peterson, P. K. (1987). Mechanism of Escherichia coli alpha-hemolysin-induced injury to isolated renal tubular cells. Am J Pathol 126, 350-357.

Kirby, J. E., Vogel, J. P., Andrews, H. L. \& Isberg, I. I. (1998). Evidence for pore forming ability by Legionella pneumophila. Mol Microbiol 27, 323-336.

Lally, E. T., Kieba, I. R., Sato, A. \& 8 other authors (1997). RTX toxins recognize a $\beta 2$ integrin on the surface of human target cells. J Biol Chem 272, 30463-30469.

Lock, R., Öhman, L. \& Dahlgren, C. (1987). Phagocytic recognition mechanisms in human granulocytes and Acanthamoeba castellanii using type 1 fimbriated Escherichia coli as phagocytic prey. FEMS Microbiol Lett 44, 135-140.

Marston, B. J., Plouffe, J. F., Breiman, R. F. \& 9 other authors (1993). Preliminary findings of a community-based pneumonia incidence study. In Legionella Current Status and Emerging Perspectives, pp. 36-37. Edited by J. M. Barbaree, R. F. Breiman $\&$ A. P. Dufour. Washington, DC: American Society for Microbiology.

Marston, B. J., Lipman, H. B. \& Breiman, R. F. (1994). Surveillance for Legionnaires' disease. Arch Intern Med 154, 2417-2422.

McClure, C. D. \& Schiller, N. L. (1996). Inhibition of macrophage phagocytosis by Pseudomonas aeruginosa rhamnolipids in vitro and in vivo. Curr Microbiol 33, 109-117.

Moffat, J. F. \& Tompkins, L. S. (1992). A quantitative model of intracellular growth of Legionella pneumophila in Acanthamoeba castellanii. Infect Immun 60, 296-301.

Morris, G. K., Patton, C. M., Feeley, J. C. \& 7 other authors (1979). Isolation of Legionnaires' disease bacterium from environmental samples. Ann Intern Med 90, 664-666.

Morris, G. K., Steigerwalt, A., Feeley, J. C., Wong, E. S., Martin, W. T., Patton, C. M. \& Brenner, D. J. (1980). Legionella gormanii sp. nov. J Clin Microbiol 12, 718-721.

Nash, T. W., Libby, D. M. \& Horwitz, M. A. (1984). Interaction between the Legionnaires' disease bacterium (Legionella pneumophila) and human alveolar macrophages. J Clin Invest 74, 771-782.

Newsome, A. L., Baker, R. L., Miller, R. D. \& Arnold, R. D. (1985). Interactions between Naegleria fowleri and Legionella pneumophila. Infect Immun 50, 449-452.

Niszl, I. A. \& Markus, M. B. (1989). Processing of free-living amoebae for transmission electron microscopy. Stain Tech 64, 259-260.

Pruckler, J. M., Benson, R. F., Moyenuddin, M., Martin, W. T. \& Fields, B. S. (1995). Association of flagellum expression and intracellular growth of Legionella pneumophila. Infect Immun 63, 4928-4932.

Reingold, A. L., Thomason, B. M., Brake, B. J., Thacker, L., Wilkinson, H. W. \& Kuritsky, J. N. (1984). Legionella pneumonia in the United States: the distribution of serogroups and species causing human illness. J Infect Dis 149, 819.

Rowbotham, T. J. (1980). Preliminary report on the pathogenicity of Legionella pneumophila for freshwater and soil amoeba. J Clin Pathol 33, 1179-1183.

Rowbotham, T. J. (1986). Current views on the relationships between amoebae, legionellae and man. Isr J Med Sci 22, 678-689.

Rowbotham, T. J. (1993). Legionella-like amoebal pathogens. In Legionella: Current Status and Emerging Perspectives, pp. 
137-140. Edited by J. M. Barbaree, R. F. Breiman \& A. P. Dufour. Washington, DC: ASM Press.

Roy, C. R., Berger, K. H. \& Isberg, R. R. (1998). Legionella pneumophila DotA protein is required for early phagosome trafficking decisions that occur within minutes of bacterial uptake. Mol Microbiol 28, 663-674.

Scheffer, J., Konig, W., Hacker, J. \& Goebel, W. (1985). Bacterial adherence and hemolysin production from Escherichia coli induces histamine and leukotriene release from various cells. Infect Immun 50, 271-278.

Segal, G. \& Shuman, H. A. (1999). Legionella pneumophila utilizes the same genes to multiply within Acanthamoeba castellanii and human macrophages. Infect Immun 67, 2117-2124.

Straub, M., Bredschneider, M. \& Thumm, M. (1997). AUT3, a serine/threonine kinase gene, is essential for autophagocytosis in Saccharomyces cerevisiae. J Bacteriol 179, 3875-3883.

Swanson, J. (1989). Fluorescent labeling of endocytic compartments. Methods Cell Biol 29, 137-151.

Swanson, M. S. \& Isberg, R. R. (1995). Association of Legionella pneumophila with the macrophage endoplasmic reticulum. Infect Immun 63, 3609-3620.

Swanson, M. S. \& Isberg, R. R. (1996). Identification of Legionella pneumophila mutants that have aberrant intracellular fates. Infect Immun 64, 2585-2594.

Venkataraman, C., Haack, B. J., Bondada, S. \& Abu Kwaik, Y. (1997). Identification of a Gal/GalNAc lectin in the protozoan Hartmanella vermiformis as a potential receptor for attachment and invasion by the Legionnaires' disease bacterium, Legionella pneumophila. J Exp Med 186, 537-547.
Vines, R. R., Ramakrishnan, G., Rogers, J. B., Lockhart, L. A., Mann, B. J. \& Petri, W. A., Jr. (1998). Regulation of adherence and virulence by the Entamoeba histolytica lectin cytoplasmic domain, which contains a $\beta_{2}$ integrin motif. Mol Biol Cell 9, 2069-2079.

Welch, R. A. (1991). Pore-forming cytolysin of Gram-negative bacteria. Mol Microbiol 5, 521-528.

Wiater, L. A., Dunn, K., Maxfield, F. R. \& Shuman, H. A. (1998). Early events in phagosome establishment are required for intracellular survival of Legionella pneumophila. Infect Immun 66, 4450-4460.

Wilkinson, H. W., Drasar, V., Thacker, W. L., Benson, R. F., Schindler, J., Potuznikova, B., Mayberry, W. R. \& Brenner, D. J. (1988). Legionella moravica sp. nov. and Legionella brunensis sp. nov. isolated from cooling-tower water. Ann Inst Pasteur Microbiol 139, 393-402.

Winn, W. C., Jr \& Myerowitz, R. L. (1981). The pathology of Legionella pneumonias. A review of 74 cases and the literature. Human Pathol 12, 401-422.

Yu, V. L., Zuravleff, J. J., Gavlik, L. \& Magnussen, M. H. (1983). Lack of evidence for person-to-person transmission of Legionnaires' disease. J Infect Dis 147, 362.

Zuckman, D. M., Hung, J. B. \& Roy, C. R. (1999). Pore-forming activity is not sufficient for Legionella pneumophila phagosome trafficking and intracellular growth. Mol Microbiol 32, 990-1001.

Received 5 November 2001; revised 18 December 2001; accepted 6 February 2002. 